\title{
Quantitative Measurement of HBeAg in Chronic Hepatitis B: A Comparison Between a Radioimmunoassay, a Fluorescence ELISA and a Chemiluminescence ELISA
}

\author{
R.A. Heijtink, J. Snobl, J. Kruining, C. Kerkhof-Los, R.A. de Man, H.L.A. Janssen, and S.W. Schalm \\ Department of Virology, Erasmus University (R.A.H., J.K., C.K.-L.), and Department of Internal Medicine II, \\ Dijkzigt Hospital (J.S., R.A.d.M., H.L.A.J., S.W.S.), Rotterdam, The Netherlands
}

The presence of the hepatitis $B$ e antigen ( $\mathrm{HBeAg}$ ) in peripheral blood of chronic hepatitis $B$ patients is a widely accepted marker of active replication of the hepatitis $\mathrm{B}$ virus. $\mathrm{HBeAg}$ determination during interferon therapy is a useful guide for the therapeutic regimen.

The aim of the study was to compare the suitability of an $\mathrm{HBeAg}$ radioimmunoassay (RIA, Abbott Laboratories, North Chicago, IL, USA), the IMx-HBeAg assay (IMx, Abbott Laboratories) and the HBeAg/anti-HBe Amerlite assay (Amerlite, Johnson \& Johnson Clinical Diagnostics, Cardiff, UK) for semiquantitative monitoring of $\mathrm{HBeAg}$ during therapy. HBeAg levels in serum samples obtained before and during interferon therapy were measured using an in-house standard calibrated against the Paul Ehrlich Institute $\mathrm{HBeAg}$ reference preparation (PEI standard).

When serial dilutions of pretreatment serum samples were assayed by the three methods, radioimmunoassay was found to be highly sensitive although it had a very limited working range (0.5 to $12 \mathrm{PEI} \mathrm{U/ml).} \mathrm{A} \mathrm{broader} \mathrm{linear} \mathrm{working}$ range was observed for Amerlite (0.5 to $50 \mathrm{PEI}$

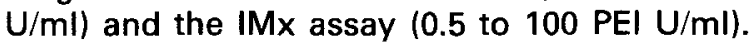
The intra-assay and interassay variations did not differ significantly. Since the IMx assay was less susceptible to sample variation and had a broad working range, semiquantitative measurement of $\mathrm{HBeAg}$ in one diluted and one undiluted sample by this assay may justifiably be introduced as routine procedure. Routine semiquantitative $\mathrm{HBeAg}$ measurement may improve individual dose adjustments and thus the success of interferon therapy. (c) 1995 Wiley-Liss, Inc.

KEY WORDS: HBV, HBeAg, immunoassay, quantification

\section{INTRODUCTION}

Several antiviral drugs and therapeutic regimens for treatment of chronic hepatitis $B$ have been studied (C) 1995 WILEY-LISS, INC.
[Main and Thomas, 1990; De Man et al., 1991]. The aim of any antiviral therapy is to suppress viral replication, leading eventually to eradication of the virus. Therapy is monitored frequently by measuring hepatitis $B$ virus DNA (HBV-DNA) by various hybridization methods. The DNA methods are expensive and usually require radioisotope facilities. Therefore, the measurement of an HBV-(antigen) marker by means of an ELISA-type method would be more convenient [Perrillo et al., 1993]. Hepatitis B e antigen (HBeAg), which is a marker of active viral replication, is used to monitor antiviral therapy. $\mathrm{HBeAg}$ seroconversion to anti- $\mathrm{HBe}$ is generally considered as an indicator of transition to a state of viral latency accompanied by normalisation of aminotransferase levels [Perrillo, 1988]. HBeAg seroconversion reduces the risk of developing cirrhosis and decompensated liver disease [Fattovich et al., 1986].

In view of the serious side effects and the high costs of treatment, clinicians tend to prescribe antiviral therapy for a minimum period. In earlier studies on interferon treatment of chronic hepatitis $B$ radioimmunoassay was used for semiquantitative determination of HBeAg [Schalm et al., 1986]. The data from this assay were of value in avoiding discontinuation of therapy just before HBeAg seroconversion [Janssen et al., 1992].

Recently, two new HBeAg assays which can also be adapted to quantify $\mathrm{HBeAg}$ have been introduced: the IMx system (Abbott Laboratories, North Chicago, IL, USA) and the Amerlite-HBeAg/anti-HBe (Johnson \& Johnson, Clinical Diagnostics, Cardiff, UK). The aim of the present study was to compare the suitability of RIA, IMx/ and the Amerlite methods for semiquantitative measurement of $\mathrm{HBeAg}$ levels during interferon therapy.

\section{MATERIALS AND METHODS Assay Systems}

The Abbott (rDNA) HBe RIA is a sandwich radioimmunoassay in which beads are coated with human poly-

Accepted for publication June 4, 1995.

Address reprint requests to Dr. R.A. Heijtink, Department of Virology, Erasmus University Rotterdam, P.O. Box 1738, 3000 DR Rotterdam, The Netherlands. 
clonal anti-HBe. $\mathrm{HBeAg}$ from serum binds to this anti$\mathrm{HBe}$ which is detected by a second incubation with human polyclonal ${ }^{125} \mathrm{~T}$-anti-HBe.

The Abbott HBeAg-IMx assay is based on microparticle enzyme immunoassay technology [Robbins et al., 1992]. Microparticles coated with human polyclonal anti-HBe are added to a serum sample. $\mathrm{HBeAg}$ from serum binds to the particles coated with anti-HBe. A monoclonal anti-HBe alkaline phosphatase conjugate is used for detection. The substrate generates a fluorescent signal.

The Kodak Amerlite immunoassay can detect either $\mathrm{HBeAg}$ or anti-HBe in a single well. In one incubation step the test sample is mixed with horseradish peroxidase (HRP)-labelled mouse monoclonal anti-HBe complexed with rDNA-HBeAg in microtitre wells coated with a second mouse monoclonal anti-HBe. The two $\mathrm{HBe}$-monoclonal antibodies differ in epitope specificity. If the patient's sample contains neither $\mathrm{HBeAg}$ nor anti-HBe, a limited signal is produced by binding of the rDNA-HBeAg-anti-HBe-HRP complex to the solid phase. In the presence of any $\mathrm{HBeAg}$ in the sample, this signal is increased, and in the presence of any anti-HBe the signal is reduced. The substrate generates a luminescent signal.

All assays were carried out according to the manufacturers' recommendations. Results were expressed as a sample to negative control signal $(\mathrm{S} / \mathrm{N})$.

\section{Standardization}

To express the amount of $\mathrm{HBeAg}$ in standard units independent of the assays, a reference preparation obtained from the Paul Ehrlich Institute (Langen, Germany) was used. This preparation is defined as containing $100 \mathrm{U} / \mathrm{ml}$ of antigen. The preparation (PEI standard) was diluted in fetal calf serum (FCS), as recommended by the manufacturer, and titrated using the three assays in parallel with a single HBeAg-positive serum sample serving as internal reference (IR). Since the PEI standard is only available in limited amounts, the IR was used throughout this study. Patient samples were diluted with FCS when necessary.

\section{Serum Samples}

For comparison of quantitative $\mathrm{HBeAg}$ measurements obtained with the three assays, pretreatment serum samples from 23 chronic hepatitis B patients were used. For evaluation of $\mathrm{HBeAg}$ in six alpha-interferon treated patients, serum samples before the start of therapy, during therapy and after therapy were assayed. Patients were treated for 16 weeks with interferon (Intron-A, $10 \mathrm{MU}$ three times a week, Schering/ Plough, NJ). All patients were tested for antibodies against human immunodeficiency virus, cytomegalovirus, Epstein Barr virus, hepatitis delta virus, and hepatitis $\mathrm{C}$ virus. No evidence of concomitant viral infections was found.

\section{RESULTS \\ Reference Preparations}

A dilution series of the PEI standard reference preparation in FCS within the range of the three tests was chosen and assayed in the same run as a twofold dilution series of the IR (Fig. 1). The dilution curves for the PEI standard and the IR were obtained with the RIA and the IMx run in parallel. In the Amerlite assay, dilution characteristics of the PEI standard and IR sample diverged. In comparison to RIA and IMx, tenfold concentrations of the PEI standard and IR had to be used to obtain signals within the range of the Amerlite assay. Due to the choice of fetal calf serum, even extensively diluted samples showed a limited signal above the cut-off level in the Amerlite assay. Fetal calf serum was nevertheless used throughout the study to avoid the need for large quantities of human serum diluent. Furthermore, $\mathrm{HBeAg}$ seroconversion was established in undiluted samples to utilize the highest sensitivity of the assay.

\section{Intra-Assay and Interassay Variation}

For assessment of the reproducibility of each assay the IR was assayed six times within the same run and once in six different runs of each assay. There were no significant differences between the three assays. The intra-assay and interassay reproducibilities ranged from $2 \%$ to $16 \%$ (Table I).

\section{Dynamic Range}

Four serum samples with high levels of HBeAg were diluted in 4-fold, 5 -fold or 10-fold steps and assayed by Amerlite, RIA and IMx, respectively (Fig. 2). For each assay the extent of the individual dilution step was obtained from pilot experiments which were intended to determine the minimal number of dilutions needed to select a fixed dilution for longitudinal observations during interferon therapy. From these curves the actual working range can be deduced. It was found that the lower and upper limits of the HBeAg level which can be detected were between 0.5 and 12 PEI U/ml for RIA, 0.5 and $100 \mathrm{PEI} \mathrm{U} / \mathrm{ml}$ for IMx and 0.5 and $50 \mathrm{PEI}$ $\mathrm{U} / \mathrm{ml}$ for Amerlite.

In both the RIA and the Amerlite assay, increasing amounts of $\mathrm{HBeAg}$ gave rise to a prozone effect in some cases. The Amerlite assay had the greatest variation in patient-specific dilution characteristics.

\section{Standardized Serum HBeAg Levels}

In an attempt to standardize test results, pretreatment samples from $23 \mathrm{HBeAg}$-positive and HBV-DNApositive patients and 22 samples obtained from six patients during therapy were assayed by each method. Within each run the IR panel was also assayed. A reference curve was constructed using the test results for the IR; by means of linear regression analysis and after correction for the dilution factor, the $\mathrm{HBeAg}$ level was expressed as PEI U/ml for each undiluted sample. Results varied from 23 to $3,609 \mathrm{PEI} \mathrm{U/ml} \mathrm{(median} \mathrm{1,080}$ 
A
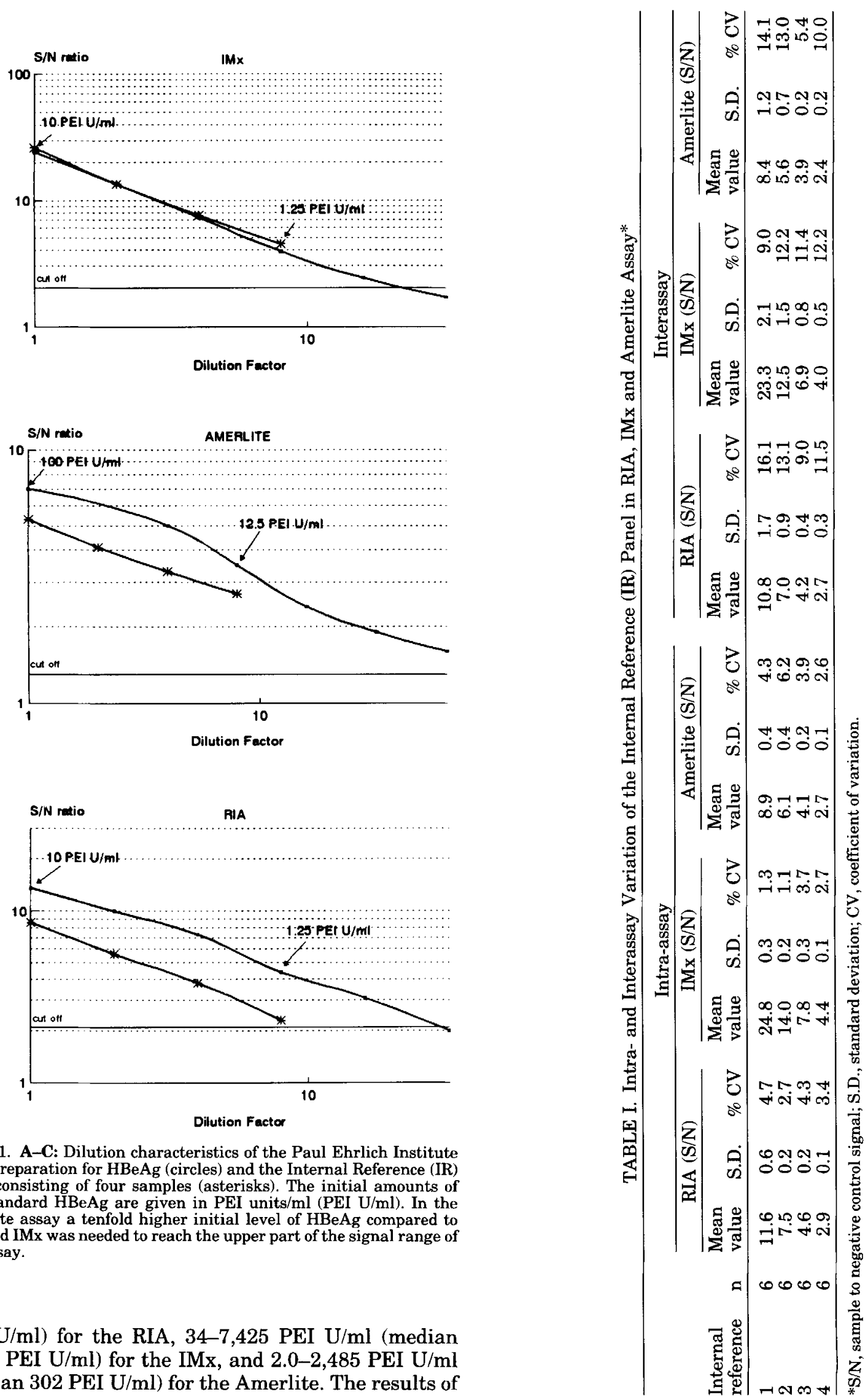

PEI U/ml) for the RIA, 34-7,425 PEI U/ml (median 1,443 PEI U/ml) for the IMx, and 2.0-2,485 PEI U/ml (median $302 \mathrm{PEI} \mathrm{U/ml)} \mathrm{for} \mathrm{the} \mathrm{Amerlite.} \mathrm{The} \mathrm{results} \mathrm{of}$

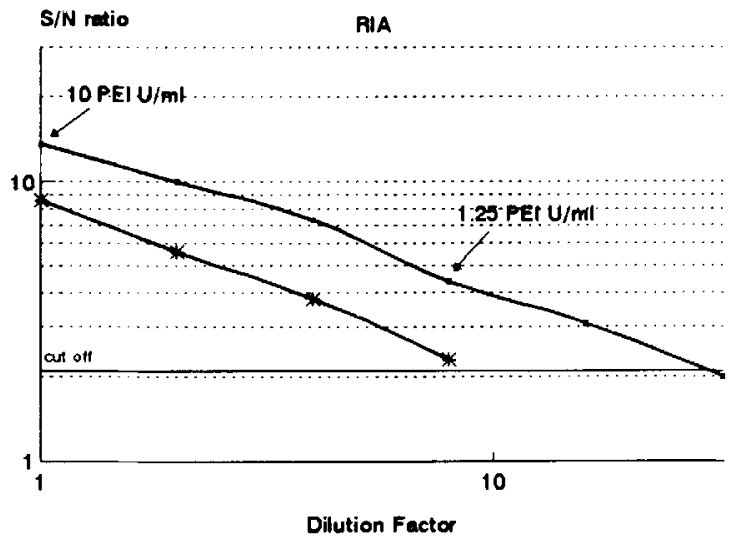

Fig. 1. A-C: Dilution characteristics of the Paul Ehrlich Institute (PEI) preparation for $\mathrm{HBeAg}$ (circles) and the Internal Reference (IR) panel consisting of four samples (asterisks). The initial amounts of PEI standard $\mathrm{HBeAg}$ are given in PEI units $/ \mathrm{ml}$ (PEI U/ml). In the Amerlite assay a tenfold higher initial level of $\mathrm{HBeAg}$ compared to RIA and IMx was needed to reach the upper part of the signal range of this assay. 
$\mathbf{A}$

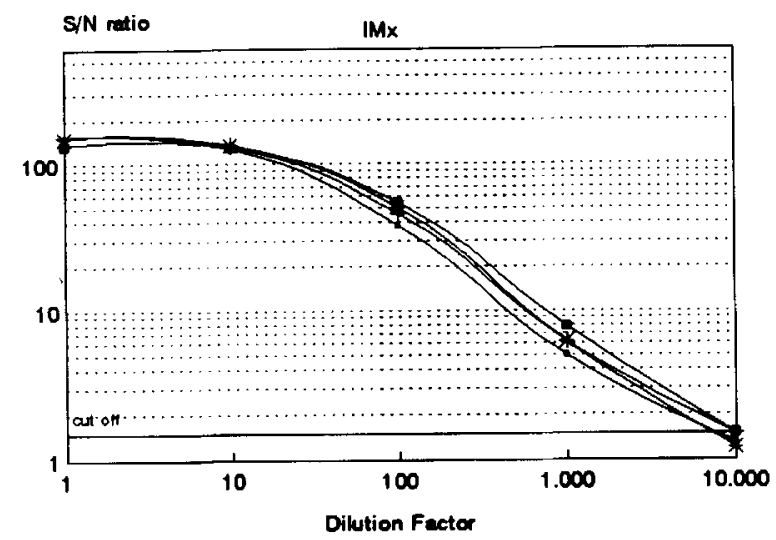

$\mathbf{8}$

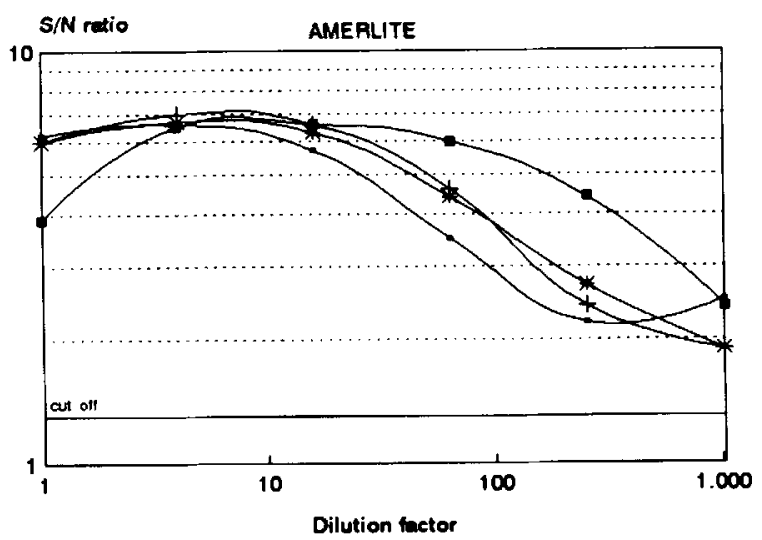

c

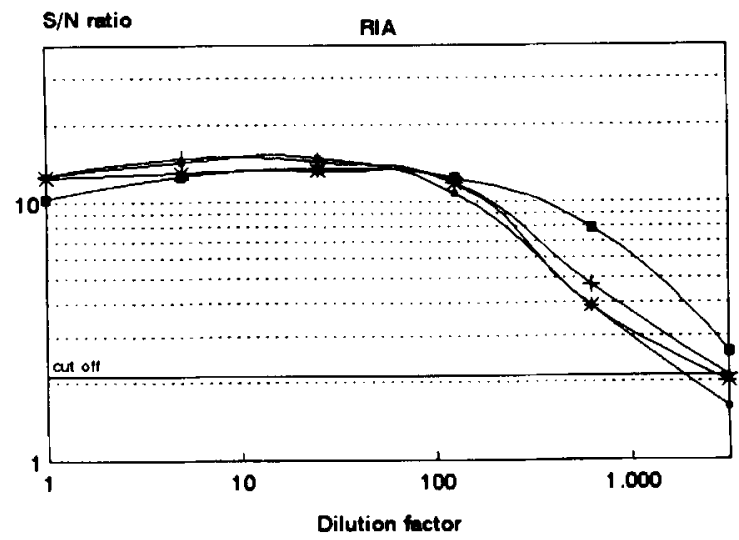

Fig. 2. A-C: Dilution characteristics of four representative pretreatment serum samples from chronic hepatitis $\mathrm{B}$ patients determined for the IMx, Amerlite and RIA. The 10-fold, 4-fold and 5-fold dilution series were tested with IMx, Amerlite and RIA, respectively. Dilution factors were chosen to cover the linear part of these curves with a minimal number of dilution steps. Dilution series started with the undiluted sample in all cases. For each patient identical symbols were used in $\mathbf{A}, \mathbf{B}$, and $\mathrm{C}$.

IMx and Amerlite are compared with the results of RIA in Figure 3. Compared to RIA, higher levels of HBeAg were observed with the IMx assay and lower levels with
A

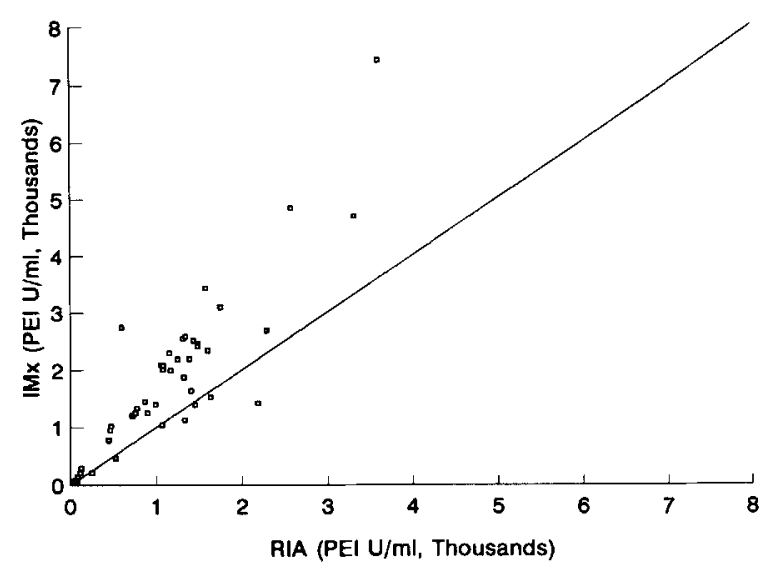

B

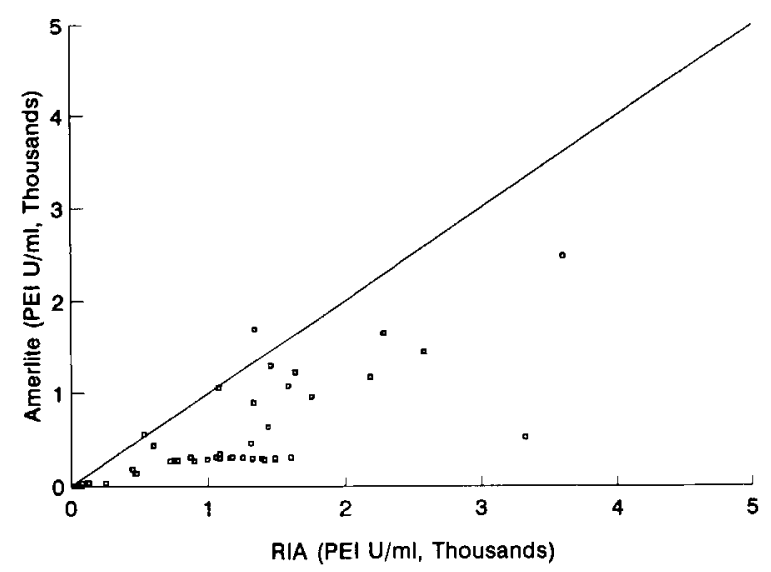

Fig. 3. A, B: Relationship between HBeAg levels determined with the IMx and Amerlite assay and the RIA using the IR after calibration with the PEI standard. For the Amerlite assay the unit of $\mathrm{HBeAg}$ was fixed at the level of $10 \mathrm{PEI} \mathrm{U} / \mathrm{ml}$ on the PEI standard curve.

the Amerlite. Spearman's coefficient for correlation of $\mathrm{HBeAg}$ levels between the radioimmunoassay and IMx and between the radioimmunoassay and Amerlite was 0.84 and 0.82 , respectively. The correlation coefficient for IMx versus Amerlite was 0.68 .

\section{Monitoring HBeAg Levels During Antiviral Therapy}

A pretreatment serum sample was titrated for each patient using the dilution series determined for each assay to find the dilution factor which would produce a signal in the upper part of the working range of the assay under study. This fixed dilution was applied to a series of serum samples from that patient. Figure 4 shows representative results for three patients during a 16-week course of interferon. When the antigen level was no longer detectable in the standard dilution, undiluted serum samples were analysed.

\section{DISCUSSION}

Clinicians who administer antiviral therapy need a reliable, reproducible and easily applicable quantita- 
A

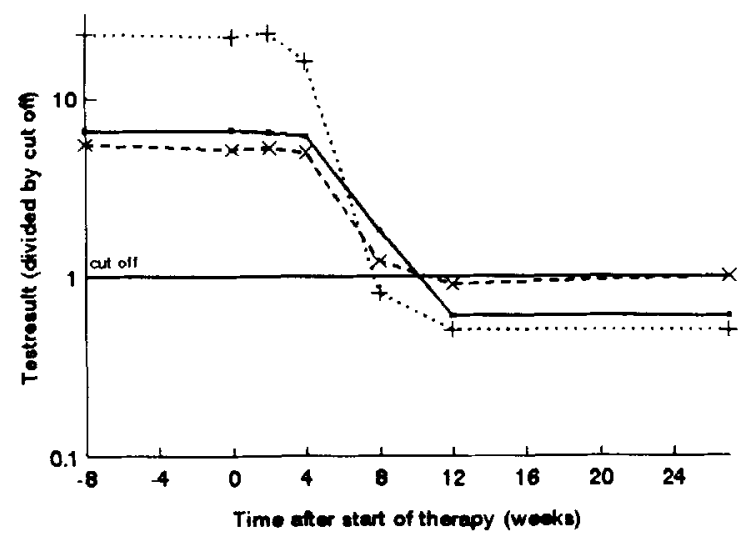

B

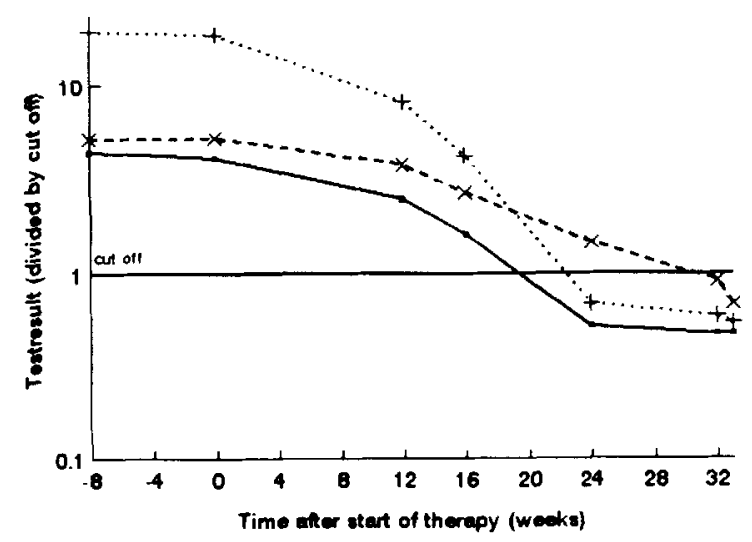

C

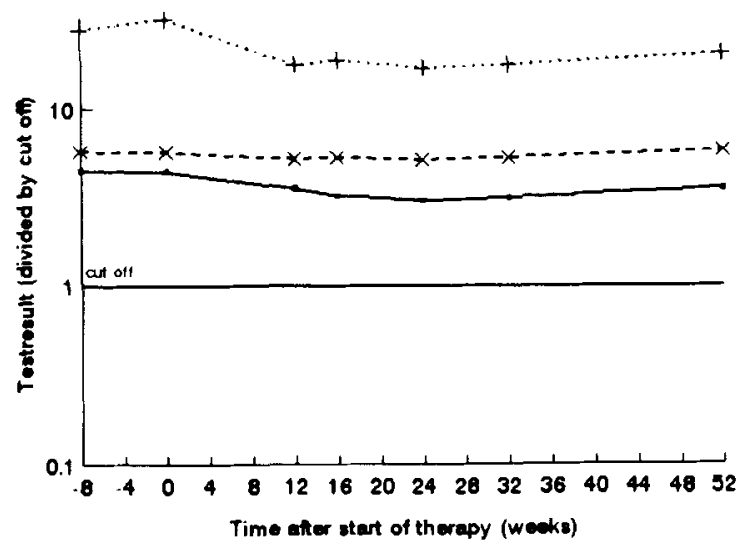

Fig. 4. A-C: HBeAg levels in serum samples from two responding and one nonresponding patient before, during and after interferon therapy. All samples from one patient were run simultaneously. Symbols: RIA, circles; IMx, crosses; Amerlite, x's.

tive assay for $\mathrm{HBeAg}$ to monitor $\mathrm{HBeAg}$ levels. The three HBeAg assays described above could be adapted for use as semiquantitative assays. Standardization of test results was one of the objectives of this study. The PEI standard preparation and an internal standard that was calibrated in PEI units by comparison of the signal with that of the PEI standard were noted.

Dilution characteristics of all samples tested were very similar by the IMx. Nonparallel dilution curves were found for RIA and the Amerlite assay. An increase in signal upon dilution of serum samples with high initial HBeAg levels was common for both RIA and Amerlite but is not easily explained.

Several investigators have described heterogeneity of $\mathrm{HBeAg}$ in patient serum [Baba et al., 1986; Matsuda and Ohori, 1988]. HBeAg epitopes may be presented by three different proteins with molecular weights ranging from $16 \mathrm{kD}$ to $20 \mathrm{kD}$ [Campillo et al., 1992]. Furthermore, these proteins may be aggregated or be immunocomplexed.

For the three HBeAg assays, anti-HBe antibody sets of different origins (mouse monoclonal, human polyclonal) were used for the adherence of $\mathrm{HBeAg}$ to the solid phase and the conjugate. The Amerlite assay may be more susceptible to structural variations of $\mathrm{HBeAg}$ than the other assays because two different monoclonal antibodies with very specific epitopes are used. In addition, in Amerlite rDNA-HBeAg is added as assay reagent to allow the detection of anti-HBe in postseroconversion samples.

Therefore, the standard that must as yet be defined for standardization should be based on several sources of $\mathrm{HBeAg}$ to diminish at least to some degree sample (patient)-specific characteristics. This study showed that there is a wide range of $\mathrm{HBeAg}$ levels in sera. For longitudinal observations during therapy using all three assays, an extended initial dilution series is required to determine a signal in the upper part of the working range of the relevant assay. The dynamic range of the assay determines the number of dilution steps which covers the whole range of possible $\mathrm{HBeAg}$ levels in unknown patient samples. The smallest number of dilution steps was found for IMx followed by Amerlite and RIA. Simultaneous assessment of an undiluted specimen and a 1/200 dilution by the IMx assay may cover the widest range, i.e., from 0.5 to about 20,000 PEI U/ml.

The intra-assay variation for all three assays was less than $6.5 \%$. The interassay variation ranged from $5 \%$ to $16 \%$. For all three assays the results are satisfactory for longitudinal studies without repeating previous samples under the condition of strict adherence to the range of the assay.

Finally, it should be noted that these HBeAg assays were not designed initially for (semi)quantification. Quantification panels for Amerlite and IMx are still under development. Nevertheless, to help estimate viral activity during interferon therapy in a routine setting these $\mathrm{HBeAg}$ assays were adapted and compared. It is concluded that the two assays, IMx and Amerlite, are more suitable for semiquantitative measurement during therapy than the RIA since both assays have a wider dynamic range under conditions of comparable reproducibility. The IMx assay was found to be less susceptible to sample-specific characteristics which 
limits the use of extended dilution series to exclude a prozone effect.

\section{REFERENCES}

Baba K, Ise I, Aihara S, Kishimoto S, Tsuda F, Tachibana K, Miyakawa Y, Mayumi M (1986): Small and large forms of hepatitis B e antigen in the serum: Determination by two-site sandwich radioimmunoassay with monoclonal antibodies. Clinical and Experimental Immunology 64:295-301.

Campillo M, Quiroga J, Bartolome J, Moraleda G, Castillo I, Carreno $V$ (1992): Protein composition of the hepatitis $B$ virus e antigen in the natural course of disease and following interferon therapy. Journal of General Microbiology 30:1256-1261.

De Man RA, Berk L, Schalm SW, Stijnen TH (1991): Treatment of chronic viral hepatitis. Digestive Diseases 9:17-35.

Fattovich G, Rugge M, Brolle L, Pontisso P, Noventa F, Guido M, Alberti A, Realdi G (1986): Clinical virologic and histologic outcome following seroconversion from $\mathrm{HBeAg}$ to antiHBe in chronic hepatitis type B. Hepatology 6:167-172.

Janssen HLA, Berk L, Schalm SW, Heijtink RA, Hess G, Rossol S, Meyer zum Busschenfelde K-H, Chamuleau RAFM, Jansen PLM, Reesink HW, Meyer B, Beglinger C, Den Ouden-Muller JW, De
Jond M, Mulder CJJ (1992): Antiviral effect of prolonged intermittent lymphoblastoid alpha-interferon treatment in chronic hepatitis B. Gut 33:1094-1098.

Matsuda K, Ohori H (1988): Immunochemical characteristics of hepatitis $\mathrm{B}$ e antigen subspecificities, $\mathrm{HBeAg} / 1$ and $\mathrm{HBeAg} / 2$. Journal of Immunology 141:1709-1713.

Main J, Thomas HC (1990): Treatment of chronic hepatitis B infection. Pharmacology \& Therapeutics 45:373-381.

Perrillo RP (1988): Antiviral therapy of chronic viral hepatitis. Gastroenterology 4:420-427.

Perillo R, Mimms L, Schechtman K, Robbins D, Campbell C (1993): Monitoring of antiviral therapy with quantitative evaluation of HBeAg: A comparison with HBV DNA testing. Hepatology 18: 1306-1312.

Robbins D, Wright T, Coleman C, Umhoefer L, Moore B, Spronk A, Douville C, Kuramoto IK, Rynning M, Gracey D, Salbilla V, Nehmadi F, Mimms LT (1992): Serological detection of $\mathrm{HBeAg}$ and anti-HBe using automated microparticle enzyme immunoassays. Journal of Virological Methods 38:267-281.

Schalm SW, Heijtink RA, Van Buuren HR, De Man RA (1986): Lymphoblastoid alpha-interferon weekly, daily and combined with acy. clovir for chronic HBeAg-positive hepatitis. Journal of Hepatology 3 (Supplement 2):S189-S192. 